volume, and others which should stem from it, should lead in constructive manner to greater understanding and skill in social control.

T. H. HAwKINS

\section{THE BEST USE OF MATHEMATICAL INNOVATION}

\section{The Best Use of Economic Resources}

By L. V. Kantorovich. English edition edited by G. Morton. Translated from the Russian by P. F. Knightsfield. Pp. xxxiii + 349. (London and New York: Pergamon Press, Ltd., 1965.) 100s. net.

THE Best Use of Economic Resources is an important book for the historian of economic thought, a valuable one for the economist anxious to improve his technical capacity, and a fascinating one for those interested in the development of the economy of the U.S.S.R.

Linear programming is a mathematical technique with many important applications in economics. Kantorovich was probably the first to use it (in 1938) and to publish on it (from Leningrad University in 1939). The first Russian edition of this book was published by the Academy of Sciences in 1959. This edition in English now enables a comparison to be made between Kantorovich's approach and the techniques independently developed since, mainly in the United States.

The book confirms the view, or prejudice, that to find close similarities in independent discovories of mathematical techniques is less surprising than, for example, in theoretical model building. Even where Kantorovich considers that his methods differ significantly, for example, from Dantzig's simplex-method, the similarities seem greater than he imagines. The references Kantorovich cites to the American work are very early ones and perhaps he was unaware of the extent to which their refinements paralleled his own.

Kantorovich's exposition of his techniques is admirably lucid, well stocked with helpful numerical examples and requires only a minimum of elementary algebra from the reader. One problem dealt with is how best to allocate a desired output of two (later three) products between a number of factories. Another is how to determine the best combination of factors of production with which to produce a given commodity. Kantorovich's concept of 'objectively determined valuations' plays a key part in his techniques for taking optimum decisions. These 'shadow prices' are used to determine the least-cost combination of factors of production and the allocation of output between enterprises. These methods of picking out least-cost solutions from a wide range of complicated possibilities are surely among the most important contributions made by mathematicians to laying foundations for human happiness.

Where Kantorovich touches on the relationship between tho process of pricing and allocating factors of production on the one hand and the pricing of commodities on the other, his exposition is not so clear. When he wrote this book Kantorovich was trying to convert Russian planners to the uso of more cost-conscious criteria when taking decisions about production. This ran into ideological resistance, because of the view that any identification of costs with scarcity was a challenge to Marx's labour theory of value. Soveral critical qualifications of this sort are made by the late V. S. Nemchinov in an editorial preface. To argue that scarcity should determine commodity prices was open to additional criticisms, of subjectivity and of suggesting that market forces should supplement or supplant decisions on priorities taken by the planners. Planning methods in the U.S.S.R. have made progress in the seven years since this book was first published, with enterprises enjoying greater autonomy to enable them to respond to the market forces which now exert considerably greater influence on the pattern of production. Much that was either obscure to Kantorovich (or obscured by him) would probably now be treated with greater clarity and directness.

Even now, of course, Russian economists would not claim that this partial equilibrium analysis could be integrated into a general equilibrium system. Their situation in this respect is little different in practice from that of Western economists, who recognize that because of the structure of industry in advanced capitalist economies the integration of their partial and general equilibrium analyses can only take place in theory. But it is useful to have a general equilibriun theory, if only to provide a contrast to the way the economy works in practice. Kantorovich's book is not an attempt at a general equilibrium theory of a planned socialist economy, and so far as I am aware, Russian economists have not yet produced such a general idealized model of their planning system. The changes in economic thinking and practice in the U.S.S.R. bring nearer the time when somebody could.

K. J. W. Alexander

\section{RULE-OF-THUMB STATISTICS}

\section{Statistical Methods}

By Prof. Stefan Szulc. Translated from the Polish by J. Stadler. Translation edited by H. Infeld and C. D. I. Forrester. Pp. viii +666. (London and New York: Pergamon Press, Ltd.; Warszawa: Państwowe Wydawnictwo Ekonomiczne, 1965.) 105s. net.

THE title Statistical Methods is a slight misnomer. The book is almost exclusively concerned with the collection and presentation of statistical data, mostly of a demographic or economic nature. It discusses, though not very thoroughly, data processing, but punched cards and the machines associated with them are described as if they were the most modern thing in a statistician's equipment; electronic computers are not mentioned at all. This probably explains why the calculation of multiple correlation coefficients is regarded as "very arduous" (p. 489).

The concept of probability is discussed only in a chapter of sixteen pages towards the end of the book. An idea of the vagueness of the treatment can be derived from the following 'definition', set out in italics: "The probability of an event is the ratio of the number of cases favouring the event to the number of all possible cases (those favouring the event and those not) assuming that all these cases are equally possible" (p. 505). The late author admits, it is true, that "this definition is not correct from the formal point of view", but no correct definition is given later. Thereafter one is not surprised to find no mention of the concept of a probabilistic model, without which no statistical interpretation of raw data is possible. This applies, in particular, to the problem of smoothing statistical data, eliminating random disturbances, and discovering trends; but then this question is treated in advance of the little chapter on probability. The vagueness of the approach to theoretical considerations is further illustrated by the following sentence: "The property of the averages is that by substituting an appropriate average for the particular values of the variable we obtain for the whole population the same result as we would get by taking into account individual values corresponding to particular observations" (p. 170).

This quotation gives also an idea of the quality of the translation. One cannot expect high standards when publishers use translators whose work has to be 'edited' by somebody else. In any event, the editors failed, for example, to provide references to existing English translations of books quoted in Polish translations; however, 